\title{
Effect of Physalis Angulata L. Leaf Water Extract on Malondialdehyde (MDA) Testis, Calcium Intracellular Sperm and Total Motile Sperm of Male Wistar Rats (Rattus Novergicus) Model of Hypertension
}

\author{
Ayu Munawaroh Aziz ${ }^{1}$, Nur Permatasari², Setyawati Soeharto ${ }^{2}$, Dian Nugrahenny ${ }^{3}$ \\ ${ }^{1}$ Lecture, Histology Laboratorium, Medical Faculty, University of Jember, Jember, Indonesia, ${ }^{2}$ Associate Professor, \\ Pharmacology Laboratorium, Medical Faculty, University of Brawijaya, Malang, Indonesia, ${ }^{3}$ Assistance Professor, \\ Pharmacology Laboratorium, Medical Faculty, University of Brawijaya, Malang, Indonesia
}

\begin{abstract}
Background: Determining the sperm quality can be measured by calculating sperm motility and sperm motility is governed by intracellular calcium $\left(\mathrm{Ca}^{2+}\right)$ concentration. However, the intracellular calcium increase found in essential hypertension cases may decrease acrosome reaction and increase ROS production, and may trigger sperm cell apoptosis. Ground cherry (Physalis angulata L) is an herbal plant containing bioflavonoid as antioxidant which is crucial to defend against free radicals and prevent toxic effects.

Objective: This study aims to test the capacity of Physalis angulata L. extract, in preventing disruption of sperm motility in male Wistar strain rats model of hypertension through oxidative stress reduction and cytosolic calcium regulation.

Method: Experimental animal male white rat (Rattus novergicus) model of hypertension were intraperitoneally inducted with L-NAME. The animals were divided into 5 treatment groups and given Physalis angulata L. leaf water extract with various doses for 14 consecutive days. At the end of the study, animals were sacrificed, and testes were taken for measuring the MDA levels, intracellular calcium, and sperm motility.

Results: Physalis angulata L. leaf water extract is proven to prevent increasing number of testicular MDA level, prevent increasing number of sperm intracellular calcium, and prevent decreasing number of motile sperm in male white Wistar strain rat model of hypertension.

Conclusion: The results show that the Physalis angulata L. leaf water extract is proven to prevent the increase of MDA testis level and the increase of intracellular calcium testis amount, and prevent the number of motile sperm on male Wistar strain white mice model of hypertension.
\end{abstract}

Keywords: Physalis angulata L., malondialdehyde (MDA), Sperm Intracellular Calcium, motile sperm, Hypertension.

\section{Introduction}

Infertility is defined as a failure to pregnant after one

\section{Corresponding Author:}

\section{Nur Permatasari}

Associate Professor, Pharmacology Laboratorium,

Medical Faculty, University of Brawijaya, Malang,

Indonesia

e-mail: nungky.permatasari@gmail.com year of attempting pregnancy by having regular sexual intercourse without contraception ${ }^{(1)}$. Among men with an average age of 38 years, $44 \%$ has infertility due to hypertension that results in testicular organ damage, but the mechanism remains unclear. In hypertension, ROS increases. It is strongly suspected that oxidative stress due to hypertension plays an important role in infertility pathomechanism ${ }^{(2-5)}$. At the cellular level, Reactive Oxygen Species (ROS) has a toxic effect that can damage sperm $^{(4,6)}$. 
The sperm quality can be measured by calculating sperm motility because it reflects the normal development and maturation of spermatozoa in epididymis. Sperm motility is governed by intracellular calcium $\left(\mathrm{Ca}^{2+}\right)$ concentrations ${ }^{(7)}$. In the homeostatic state, calcium $\left(\mathrm{Ca}^{2+}\right)$ is the second messenger that regulates cell function, including sperm cells ${ }^{(8)}$. However, an increase in intracellular calcium found in cases of essential hypertension may decrease acrosome reaction and increase ROS production, which in turn triggers apoptosis in sperm cells. Apoptosis induction can increase ROS production in intertesticular levels that reduces fertility in men ${ }^{(9)}$.

Ground cherry (Physalis angulata L.) is an herbaceous plant containing saponins, flavonoids, and also polyphenols ${ }^{(10)}$. Bioflavonoid is an antioxidant that plays an important role as a scavenger of free radicals from a disease, aging, and toxic effects of a substance ${ }^{(4)}$. Previous studies have shown that Physalis angulata L. has the ability to suppress lipid peroxidation evaluated by MDA level measurement ${ }^{(11)}$.

This study aims to test the capacity of Physalis angulata $L$. extract in preventing disruption of sperm motility in male Wistar strain rats model of hypertension through oxidative stress reduction and cytosolic calcium regulation.

\section{Material and Method}

The capacity is measured through MDA testicular measurement, calculation of spermintracellular calcium and sperm motility. This study Male used white wistar strain rats (Rattus novergicus) aged 2-3 months, and 150-200 gram in weight as experimental animal. The experimental animals model of hypertension were inducted with L-NAME intraperitoneally with systolic blood pressure $>120 \mathrm{mmHg}$. The simplicia ingredient used was Physalis angulata L. leaf water extract obtained and identified from Materia Medika Medicinal Plant Body, Batu-Malang.

Experimental Protocol: In this study the rats were divided into 5 groups, i.e. negative control (1) given NS solution intraperitoneally without treatment, positive control group (2) hypertension without treatment, group 3 (3) hypertension + treatment dose of $250 \mathrm{mg} / \mathrm{kgBW}$, group 4 (4) hypertension + treatment dose of $500 \mathrm{mg} /$ $\mathrm{kgBW}$, and group 5 (5) hypertension + treatment dose of $1000 \mathrm{mg} / \mathrm{kgBW}$. Induction of hypertension and administration of extract were given simultaneously for 14 consecutive days. Induction of hypertension was using L-NAME $40 \mathrm{mg} / \mathrm{kgBW}$ intraperitoneally ${ }^{(4)}$.

MDA Testis: MDA level calculation is the measurement indicator of oxidative stress measured on mouse testicular organs. MDA tissue was measured using Thiobarbituric Acid test. The specimen tissues were weighed as much as 0.1 grams and then homogenized and added Trichloracetic Acid (TCA) 15\%, Thiobarbituric Acid $0.375 \%$ and $0.25 \mathrm{~mol} / \mathrm{l} \mathrm{HCL}$ (in a comparison of $1: 1: 1)^{(12)}$. Then it was heated for 15 minutes on boiling water. After cooling, the precipitate in the tube was separated by centrifuging at $1000 \mathrm{rpm}$ for 10 minutes. Then the supernatant absorbance was calculated using spectrophotometry at a wavelength of $532 \mathrm{~nm}^{(4)}$.

Sperm Suspension: Cauda epididymis was taken and inserted into a petri dish containing $\mathrm{NaCl} 0.9 \%$ solution, chopped with a scalpel until the liquid was cloudy. The obtained spermatozoa suspension can be used for the analysis of the number of spermatozoa motility and Sperm Intracellular Calcium.

Sperm Intracellular Calcium: $10 \mu \mathrm{l}$ sample of sperm suspension was added with $10 \mu$ of Fluo-3 (Sigma-Aldrich) $40 \mu \mathrm{M}$, and then it was incubated for $30 \mathrm{~min}$. Then $60 \mu \mathrm{l}$ PBS (-) was added and centrifuged at $1500 \mathrm{rpm}$ for 5 minutes, it was then observed under Olympus FV 1000 confocal microscope. The PBS (-) is without $\mathrm{Ca}$ and $\mathrm{Mg}$ content. PBS (-) composition consisted of $\mathrm{NaH}_{2} \mathrm{PO}_{4} 18 \mathrm{~g}, \mathrm{NH}_{2} \mathrm{PO}_{4} 0.64 \mathrm{~g}, \mathrm{NaCl} 4 \mathrm{~g}$ and then sterilized water was added until reaching 250 $\mathrm{ml}$ in volume.

The Number of Motile Sperm: The evaluation was done by observing spermatozoa in ten different fields of view with $400 \mathrm{x}$ magnification light microscope. The spermatozoa would then be grouped into several categories according to WHO criteria of progressive mobility $(A+B)$, non-progressive mobility $(C)$, and immobile (D) ${ }^{(13)}$.

Statistical Analysis: One-Way ANOVA Test was used to see all treatment groups, and continued with Post hoc test. Pearson - Linear Regression correlation analysis was used to analyze the relationship of dose and motility. Meanwhile, Path Analysis was used to analyze the relationship between variables. 


\section{Results}

MDA Testis: Notation differences in the histogram describe that there are significant differences based on Tukey test $(p<0.05$; figure 1$)$. The testicular MDA levels of the positive control were significantly higher compared to the negative control. The MDA testicular level at dose 1 was significantly lower compared to the positive control but not significant to the negative control.

Sperm Intracellular Calcium: The amount of intracellular calcium was calculated based on Fluo-3AM color intensity observed under a confocal microscope (figure 2). The amount of sperm intracellular calcium of positive control was significantly higher compared to that of the negative control. The amount of sperm intracellular calcium in all three doses was significantly lower compared to the positive control (figure 3).

The Number of Motile Sperm: The motile sperm number of positive control was significantly lower compared to the negative control (figure 4). The numbers of motile sperm in all 3 doses were significantly higher compared to the positive control but not significant to the negative control.
The Effect of MDA Testis and Sperm Intracellular Calcium on Sperm Motility: Based on the result of testicular MDA correlation, $r$ value $=0.789$ with $p=$ 0.002 was obtained which means that there is a very strong and significant correlation between the doses of ground cherry leaf water extract with testicular MDA levels. Based on path analysis, results were obtained as in Figure 5. The results of this study show that MDA testis and sperm intracellular calcium do not significantly influence the number of motile sperm.

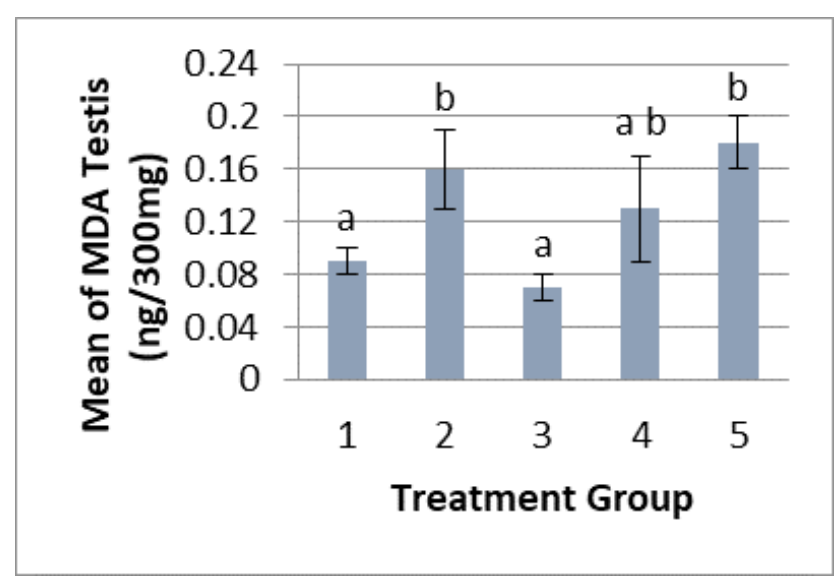

Figure 1. Diagram of the Mean and Standard Deviation of Malonaldehide (MDA) Testis Levels.

A

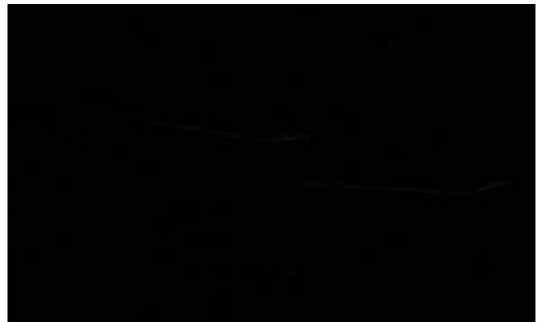

$\mathrm{C}$

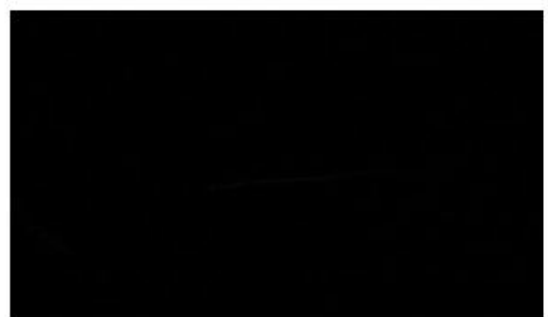

B

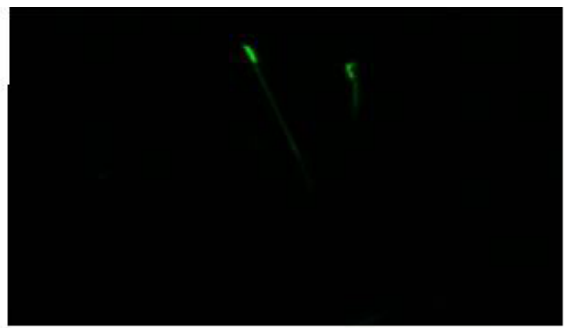

D

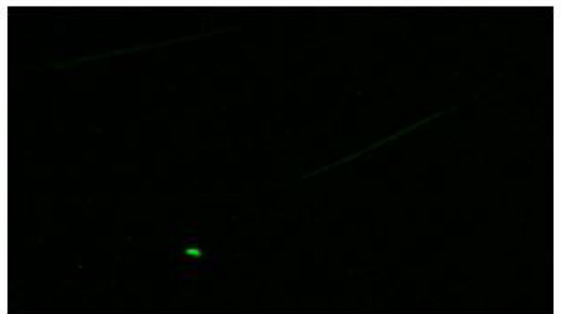

$\mathrm{E}$

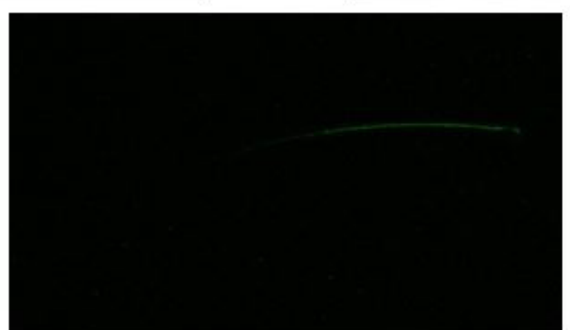

Figure 2. Results of sperm staining with fluo-3AM 


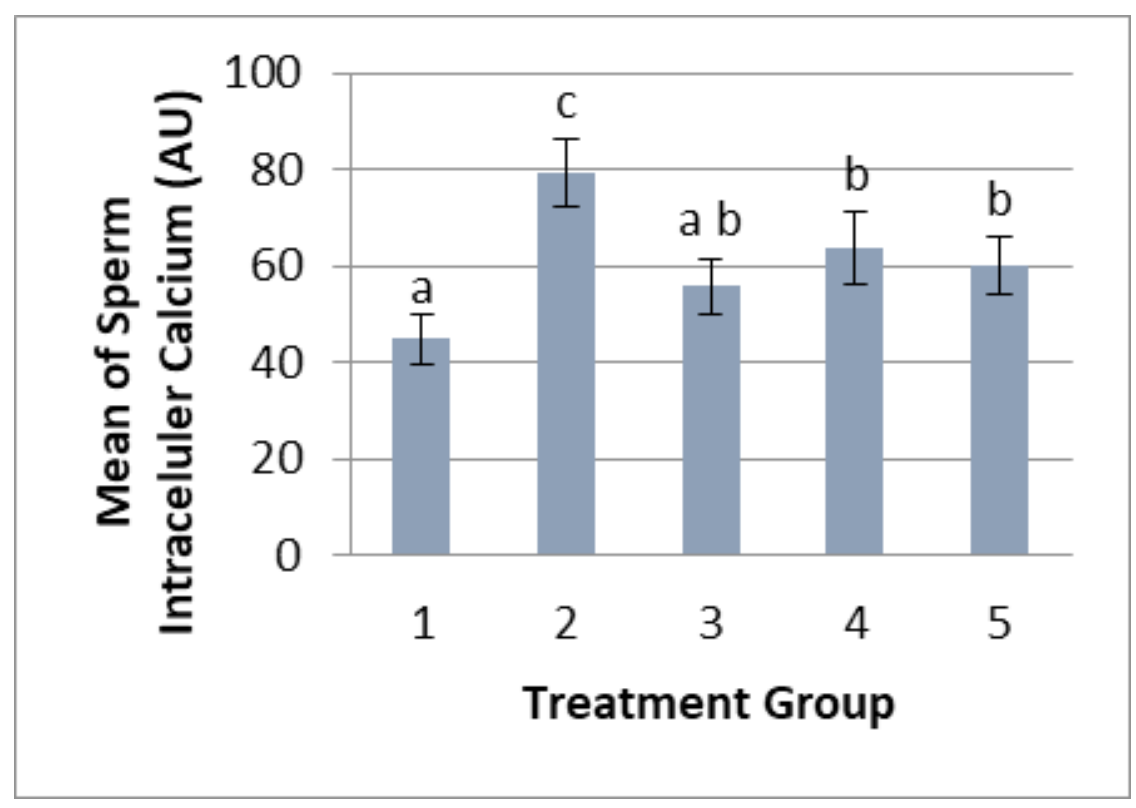

Figure 3. The Mean and Standard Deviation of sperm intracellular calcium amount.

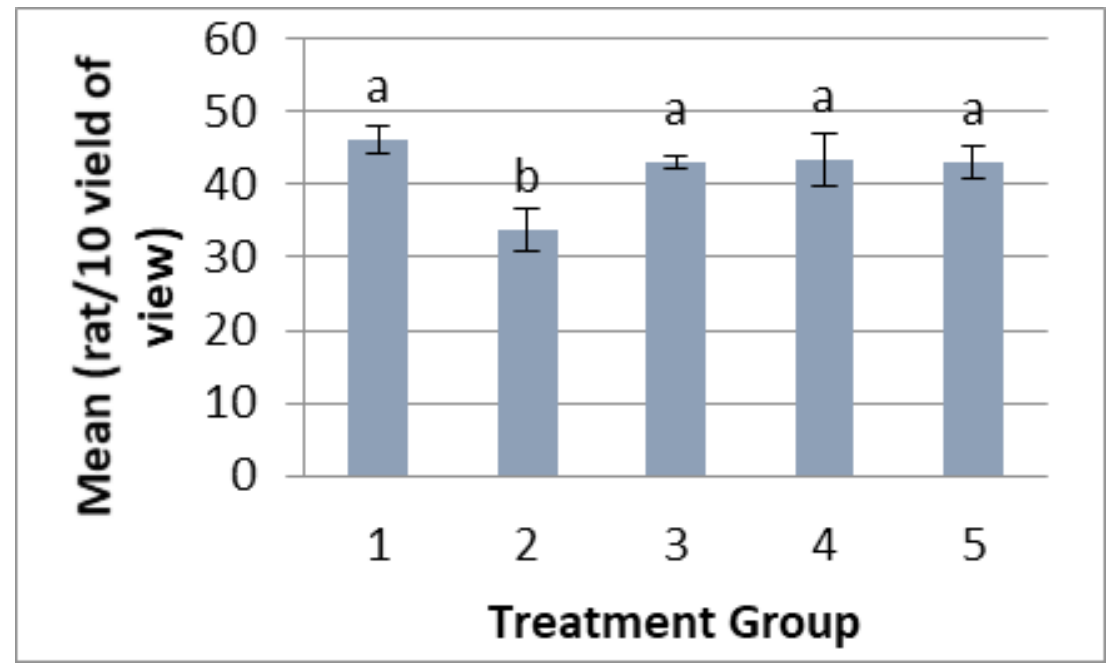

Figure 4. The mean and standard deviation of motile sperm number.

\section{Discussions}

Testicular MDA levels were significantly higher in the positive control group compared to the negative controls. L-NAME-induced hypertension condition increases both vascular and systemic oxidative stress characterized by decreased antioxidant activity in the testes and increased lipid peroxidation due to decreased NO bioavailability ${ }^{(4)}$.

The lowest testicular MDA content was found in the treatment group given Ground cherry leaf water extract of $250 \mathrm{mg} / \mathrm{kgBW}$ and was not significantly different from negative control. It shows that a dose of $250 \mathrm{mg} /$ $\mathrm{kgBW}$ of Ground cherry leaf water extract can lower testicular MDA level to normal. This is caused by the antioxidant content of Ground cherry leaf water extract. Antioxidants are compounds that can delay, slow down, and prevent lipid oxidation processes. The inhibition mechanism of lipid peroxidation by Physalis angulata L. leaf water extract involves compounds that are capable of counteracting free radicals. One of the compounds that can inhibit lipid peroxidation to capture free radicals is polyphenol compounds, especially flavonoid compounds (14). Flavonoid ability as antioxidants is because flavonoids act as free radical scavengers. The presence of a 3 ', 4' (ortho-dihydroxy) hydroxyl group on flavonoid $\mathrm{B}$ ring, 2,3 conjugated double bond with 4-oxo group (1.4-pyrrole group) on $\mathrm{C}$-flavonoid ring and 
hydroxyl group (5-OH) on flavonoid ring $\mathrm{A}^{(14)}$. Several studies have concluded that bioflavonoids can prevent changes of tissue function by increasing NO level in the testicular tissue ${ }^{(4)}$. Thus, Physalis angulata L. leaf water extract can be used to prevent elevated testicular MDA level at doses of $250 \mathrm{mg} / \mathrm{kgBW}$. Increased MDA level in the treatment groups can be assumed as an early marker of the pathogenesis of complications. This is consistent with research that conclude that MDA levels determine the pathogenesis of type $2 \mathrm{DM}$ complications because increasing MDA illustrates antioxidant use to fight free radicals which leads to a decrease in total antioxidant status $(15,16)$.

The results of this study revealed that the amount of sperm intracellular calcium was significantly higher in the positive control group compared to the negative control. This is due to a condition in hypertension from L-NAME induction, decreasing NO bioavailability and increasing ROS occur ${ }^{(4)}$. The decrease in Nitric oxide (NO) causes soluble guanil cyclase (sGC) not to be activated. As a result, the concentration of cyclic Guanin Monophosphate (cGMP) decreases and calcium increases. The decrease of cGMP gives an effect to inactivate the potassium channel so that the calcium canal is open due to increased voltage, so that there is an increase of $\mathrm{Ca}^{2+}$ entry to intracellular ${ }^{(17)}$.

In addition, the amount of intracellular calcium is also affected by ROS. ROS can induce increased cytosolic $\mathrm{Ca}^{2+}$ concentration through releasing from its storage and due to changes in clearance system. In oxidative stress state, there is an imbalance between calcium release and its storage. In mitochondrial dysfunction, there is an increase in $\mathrm{Ca}^{2+}$ uptake and $\mathrm{Ca}^{2+}$ release and in the endoplasmic reticulum $\mathrm{Ca}^{2+}$ uptake also increases. Therefore, an increase in intracellular $\mathrm{Ca}^{2+}$ happens ${ }^{(18,19)}$.

In all three doses administered to the treatment groups, the amount of sperm intracellular calcium was significantly lower compared with the positive control group. The possible mechanism of antioxidant action of Physalis angulata L. leaf water extract was through increased NO. Previous research have shown that Physalis angulata L. leaf extract can increase NO. It may cause soluble guanil cyclase to be activated and results in an increase in cGMP concentration which then affects on intracellular calcium reduction ${ }^{(17)}$.

The other possibility was mechanisms such as antioxidant activity contained in Physalis angulata $L$. leaf water extract. One of the antioxidant contents is the phenol group ${ }^{(20)}$. Reactive Oxygen Species (ROS) in the body is controlled by the body's antioxidant system. If stress oxidative state is suppressed, mitochondrial dysfunction decreases as a result of decreased $\mathrm{Ca}^{2+}$ uptake and $\mathrm{Ca}^{2+}$ release, and in the reticulum endoplasm, $\mathrm{Ca}^{2+}$ uptake also decreases. As a result, $\mathrm{Ca}^{2+}$ intracellular decreases ${ }^{(18)}$. To prove the exact mechanism of the role of Physalis angulata L. leaf water extract in intracellular calcium regulation, further study are needed. Therefore, it can be concluded that the three doses given of Physalis angulata $L$. leaf water extract can decrease the amount of sperm intracellular calcium.

The data analysis results showed that the number of motile sperm was significantly lower in the positive control when compared to the negative control. This is because the hypertension condition from L-NAME induction decreased $\mathrm{NO}$ bioavailability and increased ROS (4). L-NAME administration will inhibit NO biosynthesis process. Endothelial nitric oxide synthase (eNOS) activity is inhibited by arginase which will hydrolyze 1-arginine into 1-ornithine and urea, so NO availability decreases. As a result, vasoconstriction of blood vessels happen that causes decreased blood flow in vital organs including testes ${ }^{(17)}$.

Excessive ROS in hypertension causes cell membrane damage because the cell membrane consists of fatty acids, which can be oxidized (lipid peroxide) and the cytoplasm has only small concentration of enzyme to neutralize ROS. Lipid peroxidation on the cell membrane cell causes cell membrane to lose its integrity and increase the permeability, so it inactivates cellular enzymes, DNA damage, and cell apoptosis, and resulting in decreased number of sperm, activity, motility, and morphological changes ${ }^{(4)}$.

However, data analysis on all three doses showed a significantly higher number of motile sperm compared to the positive control. This can be because of the role of $\mathrm{NO}$ and antioxidants contained in Physalis angulata $L$. leaf water extract. Previous research show that Physalis angulata $L$. leaf can increase NO. NO affects increased sperm motility through dissolved gallyl cyclase (sGC) activation. Increased NO will be followed by increased cGMP cystesis ${ }^{(21)}$. In addition, NO can also increase motility through increased energy production in mitochondria ${ }^{(22)}$. Another mechanism that is assumed to be involved in increasing number of motile sperm 
is the activity of antioxidants. Reactive Oxygen Species (ROS) in the body is controlled by the body's antioxidant system. So it is assumed that the antioxidant activity in Physalis angulata L. leaf water extract can decrease ROS as free radical, so the number of motile sperm increases. Thus it can be concluded that three given doses of Physalis angulata L. leaf water extract can increase the number of motile sperm.

This study shows that the levels of testicular MDA and sperm intracellular calcium can not be used as variables that directly or indirectly affect sperm motility. This is consistent with the other research showing that administration of Physalis angulata $L$. ethanol extract may have hypoglycemic effects without affecting sperm quality ${ }^{(23)}$. Sperm motility can also be influenced by several factors, such as sperm flagelar length, intracellular $\mathrm{pH}$, and intracellular calcium (24). Spermatogenesis abnormalities are influenced by endogenous and exogenous factors. Endogenous factors include hormon, psychology, and genetic. Exogenous factors can be chemical, drug, heavy metals, temperature, $\mathrm{X}$-ray radiation, ultrasonic vibration, vitamin, nutrition, trauma, and inflammation. The effects of heavy metals such as lead also affect spermatogenesis process resulting in decreased sperm quality in terms of number, morphology, morphology, motility and abnormal forms of spermatozoa ${ }^{(25)}$.

\section{Conclusions}

Administration of Physalis angulata L. leaf water extract dose of $250 \mathrm{mg} / \mathrm{kgBW}$ is proven to prevent increasing number of testicular MDA level and prevent increasing number of sperm intracellular calcium in male white Wistar strain rat model of hypertension. Administration of the three doses of Physalis angulata $L$ leaf water extract is proven to prevent decreasing number of motile sperm in male white Wistar strain rat model of hypertension.

Acknowledgments: This study was funded by INSINAS (Insentif Riset Sinas I) RD 2016-0142. Dr. drg. Nur Permatasari MS as head of research project, who is gratefully acknowledged for his valuable discussion of this manuscript.

Ethical Approval: This study was approved by the Research Ethics Committee of Faculty of Medicine, University of Brawijaya, Indonesia (114/EC/ KEPK/03/2017).
Conflict of Interest: The authors declare that they have no conflict of interest.

Funding: None

\section{References}

1. Lewis SEM. Is sperm evaluation useful in predicting human fertility? Reproduction. 2007;134(1):31-40.

2. Kasturi SS, Tannir J, Brannigan RE. The metabolic syndrome and male infertility. Journal of andrology. 2008;29(3):251-9.

3. Virdis A, Duranti E, Taddei S. Oxidative stress and vascular damage in hypertension: role of angiotensin II. International Journal of Hypertension. 2011;2011.

4. Selamoglu Talas Z. Propolis reduces oxidative stress in 1-NAME-induced hypertension rats. Cell biochemistry and function. 2014;32(2):150-4.

5. Eisenberg ML, Li S, Behr B, Pera RR, Cullen MR. Relationship between semen production and medical comorbidity. Fertility and sterility. 2015;103(1):66-71.

6. Agarwal A. Role of oxidative stress in male infertility and antioxidant supplementation. US Kidney and Urology Disease. 2005;122.

7. Fanaei H, Keshtgar S, Bahmanpour S, Ghannadi A, Kazeroni M. Beneficial Effects of $\alpha$-Tocopherol Against Intracellular Calcium Overload in Human Sperm. Reproductive Sciences. 2011;18(10):97882.

8. Yeste M, Fernández-Novell JM, Ramió-Lluch L, Estrada E, Rocha LG, Cebrián-Pérez JA, et al. Intracellular calcium movements of boar spermatozoa during 'in vitro' capacitation and subsequent acrosome exocytosis follow a multiplestorage place, extracellular calcium-dependent model. Andrology. 2015;3(4):729-47.

9. Agarwal A, Sekhon LH. Oxidative stress and antioxidants for idiopathic oligoasthenoteratospermia: Is it justified? Indian journal of urology : IJU : journal of the Urological Society of India. 2011;27(1):74-85.

10. Patel T, Shah K, Jiwan K, Shrivastava N. Study on the antibacterial potential of physalis minima linn. Indian J Pharm Sci. 2011;73(1):111-5.

11. Dinakaran SK, Saraswathi NR, Nalini VR, Srisudharson, Bodanapu VR, Avasarala H, et al. Anti lipid peroxidation activity of Piper trioicum 
Roxb. and Physalis minima L. extracts. Pakistan journal of pharmaceutical sciences. 2011;24(3):4113.

12. Kheradmand A, Alirezaei M, Asadian P, Rafiei Alavi E, Joorabi S. Antioxidant enzyme activity and MDA level in the rat testis following chronic administration of ghrelin. 2009;41(6):335-40.

13. Blomberg Jensen M, Bjerrum PJ, Jessen TE, Nielsen JE, Joensen UN, Olesen IA, et al. Vitamin $\mathrm{D}$ is positively associated with sperm motility and increases intracellular calcium in human spermatozoa. Human reproduction (Oxford, England). 2011;26(6):1307-17.

14. Amić D, Davidović-Amić D, Bešlo D, Trinajstić N. Structure-radical scavenging activity relationships of flavonoids. Croatia Chemica Acta. 2003;76(1):55-61.

15. Duman BS, Oztürk M, Yilmazeri S, Hatemi H. Thiols, malonaldehyde and total antioxidant status in the Turkish patients with type 2 diabetes mellitus. The Tohoku journal of experimental medicine. 2003;201(3):147-55.

16. Rani AJ, Mythili SV. Study on total antioxidant status in relation to oxidative stress in type 2 diabetes mellitus. J Clin Diagn Res. 2014;8(3):10810 .

17. Schulz E, Gori T, Münzel T. Oxidative stress and endothelial dysfunction in hypertension. Hypertension research : official journal of the Japanese Society of Hypertension. 2011;34(6):66573.

18. Wang L, Cao J, Chen D, Liu X, Lu H, Liu Z. Role of oxidative stress, apoptosis, and intracellular homeostasis in primary cultures of rat proximal
Medico-legal Update, April-June 2021, Vol. 21, No. 2

75

tubular cells exposed to cadmium. Biological trace element research. 2009;127(1):53-68.

19. Galan C, Jardín I, Dionisio N, Salido G, Rosado JA. Role of oxidant scavengers in the prevention of $\mathrm{Ca}^{2}+$ homeostasis disorders. Molecules. 2010;15(10):7167-87.

20. Kusumaningtyas R, Laily N, Limandha P. Potential of Ciplukan (Physalis Angulata L.) as Source of Functional Ingredient. Procedia Chemistry. 2015;14:367-72.

21. Buzadzic B, Vucetic M, Jankovic A, Stancic A, Korac A, Korac B, et al. New insights into male (in)fertility: the importance of NO. British journal of pharmacology. 2015;172(6):1455-67.

22. Otasevic V, Korac A, Vucetic M, Macanovic B, Garalejic E, Ivanovic-Burmazovic I, et al. Is manganese (II) pentaazamacrocyclic superoxide dismutase mimic beneficial for human sperm mitochondria function and motility? Antioxidants \& redox signaling. 2013;18(2):170-8.

23. Daud D, Elias SF, Hassan FSM, Jalil MN, Tawang A. Physalis minima Linn methanolic extract reduces blood glucose level without compromising sperm quality in normoglycaemic mice. Journal of Applied Pharmaceutical Science. 2016;6(06):00811.

24. Miller MR, Mansell SA, Meyers SA, Lishko PV. Flagellar ion channels of sperm: similarities and differences between species. Cell Calcium. 2015;58(1):105-13.

25. Adnan S. Pengaruh pajanan timbal terhadap kesehatan dan kualitas semen pekerja laki-laki. Majalah Kedokteran Indonesia. 2001;51(5):16874. 